American Journal of Pharmaceutical Education 2017; 81 (5) Article 85.

\title{
RESEARCH
}

\section{Should Torsion Balance Technique Continue to be Taught to Pharmacy Students?}

\author{
Rhonda Bilger, PharmD, ${ }^{\mathrm{a}}$ Rasma Chereson, $\mathrm{PhD},{ }^{\mathrm{a}}$ Noha Nabil Salama, $\mathrm{PhD}{ }^{\mathrm{a}, \mathrm{b}}$ \\ ${ }^{a}$ St. Louis College of Pharmacy, St. Louis, Missouri \\ ${ }^{\mathrm{b}}$ Cairo University Faculty of Pharmacy, Cairo, Egypt
}

Submitted February 12, 2016; accepted July 30, 2016; published June 2017.

Objective. To determine the types of balances used in compounding pharmacies: torsion or digital. Methods. A survey was mailed to the pharmacist-in-charge at 698 pharmacies, representing $47 \%$ of the pharmacies in Missouri as of July 2013. The pharmacies were randomly selected and stratified by region into eight regions to ensure a representative sample. Information was gathered regarding the type and use of balances and pharmacists' perspectives on the need to teach torsion balance technique to pharmacy students.

Results. The response rate for the survey was 53.3\%. Out of the total responses received, those pharmacies having a torsion balance, digital balance or both were $46.8 \%, 27.4 \%$ and $11.8 \%$, respectively. About $68.3 \%$ of respondents compound prescriptions. The study showed that $52 \%$ of compounding pharmacies use torsion balances in their practice. Of those with a balance in their pharmacy, $65.6 \%$ favored continuation of torsion balance instruction.

Conclusions. Digital balances have become increasingly popular and have replaced torsion balances in some pharmacies, especially those that compound a significant number of prescriptions. The results of this study indicate that torsion balances remain integral to compounding practice. Therefore, students should continue being taught torsion balance technique at the college.

Keywords: compounding, torsion balance, digital balance, pharmaceutics

\section{INTRODUCTION}

Compounding, in this era of personalized medicine, is a crucial skill for pharmacists, the only health care professionals educated in the art and science of compounding. Recently, there has been a call for greater emphasis on uniformity and quality control in compounding. This emphasis should begin at its foundation, the education that pharmacists receive while they are in school. But instruction in compounding, including the underlying science and math, has declined over the years in part because of the inclusion of clinical coursework and experiential training. ${ }^{1}$ The Accreditation Council of Pharmacy Education (ACPE) continues to list extemporaneous compounding as a required component of any accredited pharmacy curriculum across the United States, ${ }^{2}$ yet there is no national standardized compounding education curriculum. Unfortunately, some educators now place less priority on teaching extemporaneous compounding. The

Corresponding Author: Noha N. Salama, Department of Pharmaceutical and Administrative Sciences, St. Louis College of Pharmacy, 4588 Parkview Place, St. Louis, MO 63110-1088. Tel: 314-446-8576. Fax: 314-446-8460. E-mail: noha.salama@stlcop.edu
2012 AACP Task Force on the status of compounding in education reported a range from 0 to 6 semesters of compounding education across US pharmacy schools that provided a response. ${ }^{3}$ It is not surprising that some pharmacists report they do not compound because of their lack of appropriate training. ${ }^{4,5}$

Prioritization of compounding education across pharmacy schools is clearly needed as the number of compounded prescriptions continues to grow. The 2012 AACP Task Force on the status of compounding in education supports compounding in the curriculum, with a hands-on laboratory and associated equipment and supplies. ${ }^{3}$ A 2005 survey of pharmacists in independent pharmacies (in Illinois, Missouri, Kansas, and Iowa) found $94 \%$ of respondent pharmacies provided compounding services and that $2.3 \%$ of prescriptions dispensed were for compounded medications. ${ }^{4}$ The International Academy of Compounding Pharmacists (IACP) reports that $1 \%$ to $3 \%$ of the prescriptions filled in the United States are for compounded prescriptions. ${ }^{6}$ With 4 billion prescriptions of all types filled annually, ${ }^{7}$ this translates into millions of compounded prescriptions being prepared each year. The National Community Pharmacist Association (NCPA) estimates from 30 million to 40 million 


\section{American Journal of Pharmaceutical Education 2017; 81 (5) Article 85.}

prescriptions for compounded medications are filled annually. ${ }^{8}$ A recently published study that reviewed insurance claims in 2012 and 2013 found the prevalence of compound users increased from $1.1 \%$ to $1.4 \%$ over the study period, an increase of $27.3 \%{ }^{9}$ Additionally, membership has reached 3900 for the Professional Compounding Centers of America (PCCA), ${ }^{10}$ and 4000 for the International Association of Compounding Pharmacists (IACP). ${ }^{11}$ According to the Compounding Pharmacies Market Research Report March 2016, ${ }^{12}$ the compounding industry has grown due in large part to manufacturer drug shortages and the aging population. This growth is expected to accelerate over the next five years. ${ }^{12}$

Preparation of prescriptions that are accurate is emphasized within the AACP 2016 Standards. $^{2}$ Accuracy in compounding is a fundamental skill of competent pharmacists. This includes accuracy in calculations, procedures, and all measurements, including weighing. Compounding requires the use of a precise and accurate balance to achieve therapeutic efficacy and safety for the patient. In USP Chapter $<1176>$, "Prescription Balances and Volumetric Apparatus, a prescription balance is defined as "a scale or balance adapted to weighing medicinal and other substances required in prescriptions or in other pharmaceutical compounding." 13 A "Class A" (typically referred to as class III ${ }^{14}$ balance should be used for all the weighing operations required in prescription compounding. The sensitivity requirement or limit of a Class A balance is defined as a pointer shift of not less than one index-scale division when $6 \mathrm{mg}$ has been added to a pan. The chapter does allow for balances such as micro-, semimicro-, or electronic single-pan balances to be used provided they possess equivalent or better accuracy. Chapter $<1251>$ goes on to discuss the operational and performance qualifications of an analytical balance in terms of linearity, eccentricity, sensitivity, and repeatability. ${ }^{15}$ The gold standard has been to avoid errors of $>5 \%$, although a few studies in pharmacy schools suggested that $10 \%$ may be a more realistic expectation. ${ }^{16,17}$ Repeatability and accuracy are elaborated under Chapter $<41>$ (balances). ${ }^{18}$ Of course, accuracy is dependent upon how well the balance has been maintained. The USP does not specify when or how performance qualifications should be completed, just that all equipment must be routinely inspected, calibrated as necessary and documented per standard operating procedures of the pharmacy. ${ }^{13,15,18,19}$ Missouri Department of Agriculture, Weights, Measures and Consumer Protection only certifies commercial weighing and measuring devices. ${ }^{20}$

Historically, torsion balances have been utilized in pharmacies to weigh ingredients. Hence, the torsion balance has been the sole balance utilized in the Introduction to Pharmacy Practice and Pharmaceutics laboratories at St. Louis College of Pharmacy (STLCOP). Torsion balances are relatively easy to use, durable, and accurate but require several steps in terms of equilibration, adding weight, and using the release knob each time the substance to be weighed is increased or decreased. This process can be time-consuming and can potentially lead to errors. Students spend considerable time learning how to properly use torsion balances but have expressed concerns verbally and on laboratory evaluations that this type of balance has become obsolete and are not as accurate as digital balances. This perception interferes with the level of student attentiveness during laboratory training and adversely affects student learning.

In recent years, digital balances have become increasingly popular because of their ease of use and speed of operation. Fewer steps in the weighing process should result in fewer errors and lesser time requirement. In addition, the price of a good digital balance has decreased substantially over recent years, making these balances very attractive, especially in pharmacies that compound a significant number of prescriptions. Both types of balances are considered accurate if used correctly, though their readability and sensitivity differ. Newton discussed the weighing accuracy of torsion balances as compared to digital balances. According to Newton's report, the sensitivity of torsion balances are $0.006 \mathrm{~g}$, and the smallest readable amount is $0.01 \mathrm{~g}$, whereas electronic balances can range from $0.01 \mathrm{~g}$ to $0.002 \mathrm{~g} .{ }^{21}$ A study by Kadi and colleagues compared a solution prepared by students using a torsion balance and a digital balance. There was no statistical difference in the magnitude of the error of the unacceptable formulas $(p>.05)$ and no difference in accuracy of the acceptable formulations. $^{22}$

In an effort to support current practice in pharmacy and to guide educational efforts as part of the Pharmaceutics laboratory, the Pharmaceutics team at STLCOP decided to investigate whether torsion balances continue to be the primary balance used in Missouri to compound prescriptions. The State Board of Pharmacy in Missouri does not require pharmacies to own a specific type of balance (2016 search of the Missouri code of state regulations 20CSR 2220-2.010). ${ }^{23}$ Similar statutes are found in other states, such as Texas ${ }^{24}$ and Oregon. ${ }^{25}$ In some states, such as Wisconsin, ${ }^{26}$ Virginia, ${ }^{27}$ and Illinois, ${ }^{28}$ all pharmacies must have a balance, but the type of balance is not specifically indicated. Because balances are not required, the actual numbers of torsion balances in Missouri pharmacies and the extent of their use in compounding are largely unknown. Therefore, the objective of this study was to determine the types of balances (torsion or digital) 


\section{American Journal of Pharmaceutical Education 2017; 81 (5) Article 85.}

used in compounding pharmacies in Missouri via a survey in 2014.

\section{METHODS}

There were a total of 1487 pharmacies registered with the Missouri Board of Pharmacy as of December 2013. Based on studies by Krejcie and Morgan, a representative statistical sample of this population would be comprised of 306 pharmacies. ${ }^{29}$ A survey was sent to the pharmacist-in-charge at selected pharmacies randomly chosen from the total number of pharmacies registered with the Missouri Board of Pharmacy. A total of 698 surveys were mailed (ie, $\sim 47 \%$ of the registered pharmacies). As specified by the state, Missouri is divided into eight regions: northwest, northeast, Kansas City, central, St. Louis, southwest, Ozark and southeast. The regions were numbered 1 through 8 in the order listed. There are rural and urban regions in Missouri, with substantial differences in population densities and regions showing as few as 2171 residents (as reported for Worth county, located in the Northwest region, in the 2010 census) compared to regions with almost 1 million people in St. Louis county. ${ }^{30}$ Because of this difference in communities, there is a higher concentration of pharmacies in the Kanas City and St. Louis regions. To ensure equal representation from all regions, this study targeted the same percentage $(\sim 47 \%)$ of the total pharmacies within each region.

Information was gathered regarding the type and use of balances and pharmacists' perspectives on the need to teach torsion balance technique to pharmacy students. The percent of pharmacies using torsion and/or digital balances was calculated. Comparison by region and pharmacy practice setting (independent or chain community pharmacies vs hospital pharmacies vs other settings) were investigated. The frequencies were computed using IBM SPSS descriptive statistics (Version 20).

Determination of the balance type to be used in the teaching setting was based on statistical quartiles. If the pharmacies using torsion balances were found to be more than $75 \%$, torsion balances would remain the primary balance used in laboratory instruction at STLCOP. However, if $25 \%-75 \%$ of pharmacies used torsion balances to compound, then both torsion and digital balances would be utilized in the laboratory. Less than $25 \%$ torsion balance usage would indicate that students should be exposed to torsion balances but train primarily with digital balances.

The project was exempt from review and oversight as stipulated by the St. Louis College of Pharmacy Institutional Review Board.

\section{RESULTS}

A sample of 306 responses was statistically found to be representative of the study population. There were 372 completed surveys returned out of the total 698 that were mailed (ie, 53.3\% response rate). Four surveys were returned un-delivered. The responses represented $45 \%$ to $71 \%$ of those who were contacted per region and represented $21.2 \%$ to $32.8 \%$ of the total registered pharmacies in each region (Table 1). The highest response was received from pharmacies that self-identified as chain community pharmacies $(n=162)$ followed by those that self-identified as independent community pharmacies $(\mathrm{n}=141)$. Twenty-eight pharmacies self-identified as hospital pharmacies. Therefore, $81.5 \%$ of pharmacies self-identified as community pharmacies (chain and independent), and $7.5 \%$ self-identified as hospital pharmacies. Forty-one pharmacies self-identified as "other settings." This category covered a variety of settings, including

Table 1. Missouri Pharmacies That Participated in the Survey, Stratified by Region

\begin{tabular}{|c|c|c|c|c|c|c|}
\hline \multirow[b]{2}{*}{ Region } & \multicolumn{6}{|c|}{ Number of Pharmacies } \\
\hline & $\begin{array}{c}\text { Registered with } \\
\text { Missouri Board } \\
\text { of Pharmacy }\end{array}$ & $\begin{array}{l}\text { Number of } \\
\text { pharmacies } \\
\text { contacted }\end{array}$ & $\begin{array}{c}\text { Percent of } \\
\text { total registered } \\
\text { pharmacies }\end{array}$ & $\begin{array}{l}\text { Number of } \\
\text { responses } \\
\text { received }\end{array}$ & $\begin{array}{c}\text { Percent of } \\
\text { respondents out of } \\
\text { those contacted } \\
\text { per region }\end{array}$ & $\begin{array}{c}\text { Percent of } \\
\text { respondents out } \\
\text { of all registered } \\
\text { pharmacies } \\
\text { per region }\end{array}$ \\
\hline 1 (Northwest) & 72 & 34 & 47.2 & 19 & 55.9 & 26.4 \\
\hline 3 (Kansas City) & 296 & 139 & 47.0 & 64 & 46.0 & 21.6 \\
\hline 4 (Central) & 131 & 62 & 47.3 & 36 & 58.1 & 27.5 \\
\hline 5 (St. Louis) & 501 & 235 & 46.9 & 131 & 55.7 & 26.1 \\
\hline 6 (Southwest) & 236 & 111 & 47.0 & 50 & 45.0 & 21.2 \\
\hline 7 (Ozark) & 67 & 31 & 46.3 & 22 & 71.0 & 32.8 \\
\hline
\end{tabular}




\section{American Journal of Pharmaceutical Education 2017; 81 (5) Article 85.}

long-term care facilities, government, warehouse, clinic pharmacy, mail order pharmacy, nuclear pharmacy, hospital outpatient clinic, sterile products class $\mathrm{H}$, oncology clinic, grocery chain-community, home infusion, and inpatient psychiatric facilities, among others. Figure 1 shows the relative breakdown of the types of practice sites per region and highlights the differences between the eight Missouri regions. Nonetheless, the figure indicates that despite regional differences, independent community pharmacies provided the highest response to the survey discussed herein.

The total number of pharmacies that owned a balance was 320 pharmacies out of the 372 that were returned (ie, $86 \%$ of all respondents). The vast majority of these pharmacies $(n=295)$ self-identified as one of the three major practice sites that were investigated (independent or chain community pharmacies and hospital pharmacies). The percent of pharmacies that owned balances for the three major practice sites was $90.8 \%$ of the independent community pharmacies (128 out of 141 responding pharmacies), $88.9 \%$ of chain community pharmacies (144 out of 162 responding pharmacies), and $82.1 \%$ of hospital pharmacies ( 23 out of 28 responding pharmacies). For the "other settings" category, $61 \%$ owned a balance (25 out of 41 responding pharmacies).

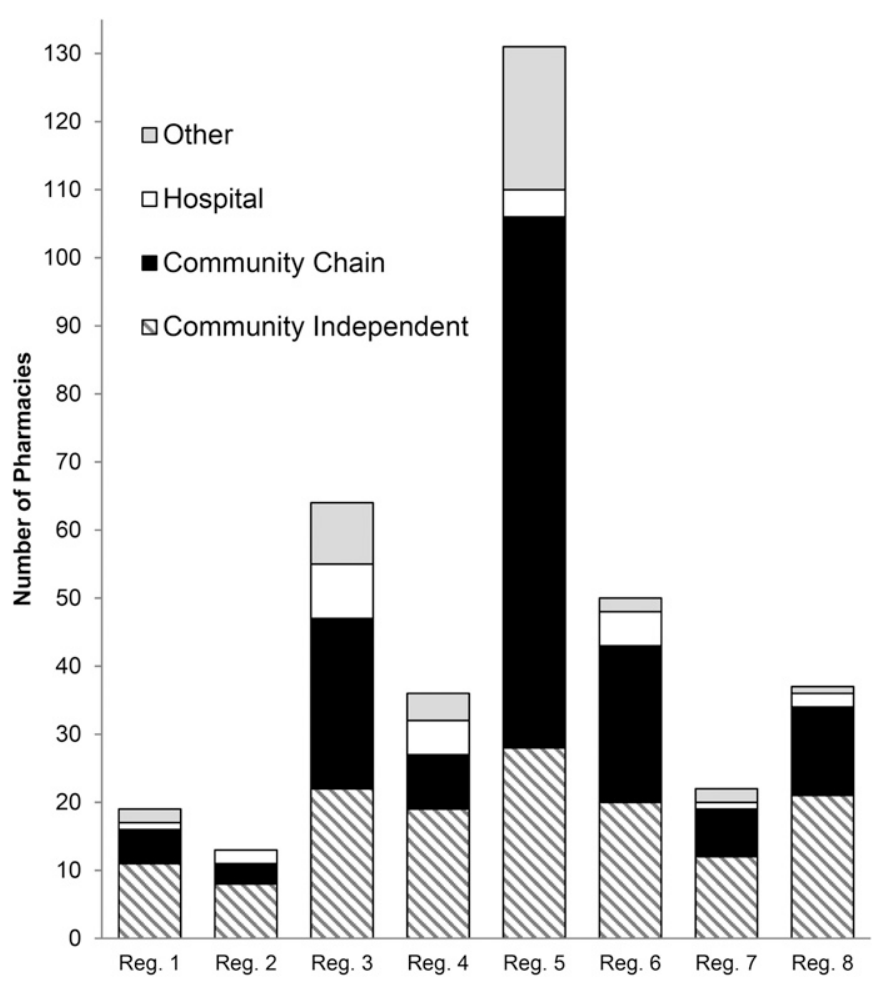

Figure 1. Breakdown of Practice Settings in Each Missouri Region.
Out of the total responses received $(n=372)$, the number of pharmacies that owned a torsion balance only, a digital balance only, or both types was 174 (46.8\%), 102 (27.4\%), and 44 (11.8\%) pharmacies, respectively (Figure 2). Therefore, the total number of pharmacies owning a torsion balance is $218(174+44$ pharmacies $)$ and constitute $58.6 \%$ of the total respondents $(n=372)$ and $68.1 \%$ out of all the pharmacies that owned a balance $(n=320)$. The three major practice settings that were investigated indicated a higher number of pharmacies owning torsion balances exclusively (Figure 2). In addition to the overall higher percent of pharmacies that owned torsion balances in this sample population, this observation was replicated in every investigated Missouri region with more pharmacies exclusively owning torsion balances compared to digital balances.

There were 254 (68.3\%) pharmacies out of 372 respondents that specified they use balances to compound prescriptions. The study revealed that $52 \%$ of compounding pharmacies use torsion balances in their practice. Therefore, the use of torsion balances fell within the $25 \%$ to $75 \%$ range based on the statistical quartiles discussed in Methods. The number of pharmacists who reported using torsion balances for compounding was quite comparable or higher than those using digital balances for all the Missouri regions surveyed except for St. Louis. In the St. Louis region, there were 12 more pharmacists who reported using digital balances compared to those using torsion balances. In all the three major investigated category practice sites, the use of a torsion balance in compounding was comparable, if not higher, to the use of a digital balance (Table 2). At pharmacies that own both torsion and electronic balances $(n=44)$, the pharmacist in charge indicated a preference for digital balances in compounding ( 32 pharmacies out of a total of 44 pharmacies) vs three who preferred using torsion balances, and three

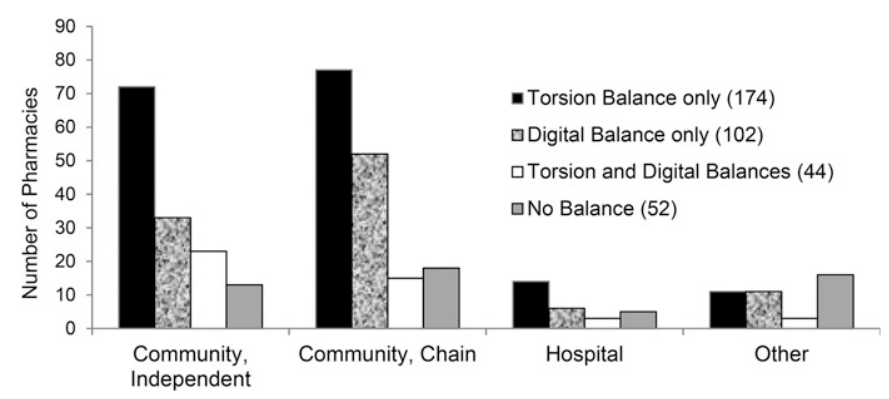

The numbers between parentheses in the legend reflect the total number of pharmacies with one type of balance, both, or none across all practice settings.

Figure 2. Breakdown of Balances Owned by Pharmacies Stratified Based on Practice Setting. 


\section{American Journal of Pharmaceutical Education 2017; 81 (5) Article 85.}

Table 2. Types of Balances Used In Compounding, Stratified Based on Practice Site

\begin{tabular}{lccrrr}
\hline & $\begin{array}{c}\text { Community, } \\
\text { Independent }\end{array}$ & $\begin{array}{c}\text { Community, } \\
\text { Chain }\end{array}$ & Hospital & Other & Total \# of pharmacies \\
\hline Torsion & 62 & 49 & 10 & 8 & $129^{\text {a }}$ \\
Digital & 51 & 51 & 8 & 12 & $122^{\text {a }}$ \\
Both & 0 & 3 & 0 & 0 & $3^{\text {a }}$ \\
Own but do not compound & 15 & 41 & 5 & 5 & 25 \\
Total \# of pharmacies that own a balance & 128 & 144 & 23 & $\mathrm{~N}=320$ Pharmacies \\
\hline
\end{tabular}

${ }^{a}$ Denotes compounding pharmacies for a total of 254 pharmacies

who used both types of balances in compounding. Of the pharmacies owning both types of balances, there were six pharmacists who specified they do not compound prescriptions.

Only 218 pharmacies of the 254 compounding pharmacies provided clear information regarding the number of compounded prescriptions on a weekly basis. For those pharmacies, the range of prescriptions compounded in the different practice settings ranged from less than 10 prescriptions per month to 1000 prescriptions per month (Table 3).

When asked for input regarding training students on the use of torsion balances, the percent of pharmacists in charge who recommended continuation of torsion balance instruction exceeded $50 \%$ for each of the investigated practice sites regardless of whether they owned balances or not and whether they used balances in compounding or not (range $\sim 51 \%$ to $71 \%$ across practice sites, Table 4). When specifically analyzing data for each Missouri region, the percent of pharmacists in charge who recommended continuation of teaching of torsion balance techniques exceeded $60 \%$ in every region except for region 5 (St. Louis), where the percent of those advocating for torsion balance instruction was $48.9 \%$. When analyzing the data for each of the main three practice sites (community-independent, community-chain, and hospital) within each region, the percent of pharmacists in charge who advocated for continuation of torsion balance

Table 3. Number of Compounded Prescriptions/Month Using Torsion, Digital or Both Types of Balances

\begin{tabular}{lccc}
\hline & $<\mathbf{1 0}$ & $\mathbf{1 0 - 1 0 0}$ & $>\mathbf{1 0 0}$ \\
\hline $\begin{array}{l}\text { Using Torsion Balance in } \\
\quad \text { Compounding }\end{array}$ & 88 & 19 & 1 \\
$\begin{array}{l}\text { Using Digital Balance in } \\
\text { Compounding }\end{array}$ & 60 & 33 & 14 \\
\hline
\end{tabular}

Two data points were excluded from the group using digital balances to compound because of lack of clarity regarding the number of compounded prescriptions

Note that three pharmacies reported using both balances in compounding instruction reached $50 \%$ or higher for each practice site except for Kansas city ( $\sim 38 \%$ out of 8 hospital sites) and the central region $(\sim 38 \%$ out of 8 community-chain sites). The majority of responding pharmacists in pharmacies that exclusively owned and used torsion balances advocated for continuation of torsion balance instruction. This observation could very possibly be driven by the exclusive availability of this specific balance. It was notable that pharmacists who exclusively use a digital balance in compounding were almost equally split in terms of advocating for torsion balance instruction in all the investigated practice settings (Table 5). Additionally, the pharmacists at pharmacies that do not compound but own a balance concurred, with 37 pharmacists advocating for continued torsion balance instruction versus 27 pharmacists who did not. Two pharmacists did not specify a preference. At pharmacies that do not own a balance $(n=52)$, the percent of pharmacists who advocated for continued torsion balance instruction was $85.7 \%$ of all those who expressed a preference $(n=14$ pharmacists $)$ but the rest of the pharmacists $(n=38)$ did not express an opinion.

\section{DISCUSSION}

Extemporaneous compounding has long been a skill practiced by pharmacists that sets them apart from all other health care professionals. It is expected that each and every prescription is prepared with the highest degree of accuracy, and the full responsibility for the compounded preparations is held by the pharmacist. Faculty at STLCOP are in agreement concerning the importance of compounding education. To guide educational efforts in compounding as part of the Pharmaceutics course laboratory, an investigation of the types of balances (torsion or digital) used in Missouri pharmacies was conducted via a mailed survey to registered pharmacies in Missouri in 2014.

In this study, data was collected regarding the current use of torsion balances in compounding across Missouri. The results of this study indicate that torsion balances remain integral to current compounding practice in Missouri with significantly more pharmacies solely owning 


\section{American Journal of Pharmaceutical Education 2017; 81 (5) Article 85.}

Table 4. Number of Pharmacists In Charge Who Encouraged the Continuation of Torsion Balance Instruction at Pharmacy Schools

\begin{tabular}{|c|c|c|c|}
\hline & $\begin{array}{l}\text { Number of Pharmacies } \\
\text { (Percent out of the } \\
\text { Total Number) }\end{array}$ & Category breakdown & $\begin{array}{c}\text { Number of Pharmacies } \\
\text { (Percent out of the } \\
\text { Total Number) }\end{array}$ \\
\hline & & Community Chain & $94(58.0 \%)$ \\
\hline & & Hospital & $15(53.6 \%)$ \\
\hline & & Other & $21(51.2 \%)$ \\
\hline balance $(n=320)$ & & Community Chain & $91(63.2 \%)$ \\
\hline & & Hospital & $13(56.5 \%)$ \\
\hline & & Other & $16(64.0 \%)$ \\
\hline \multirow{3}{*}{$\begin{array}{l}\text { Out of pharmacies using } \\
\text { balances to compound }(n=254)\end{array}$} & $173(68.1 \%)$ & Community Independent & $80(70.8 \%)$ \\
\hline & & Community Chain & $68(66.0 \%)$ \\
\hline & & Hospital & $11(61.1 \%)$ \\
\hline
\end{tabular}

a torsion balance versus those solely owning a digital one. Because a literature search revealed no other study on this subject, a comparison to other studies cannot be made. However, an explanation for the difference in the type of balance owned might be because of the prior Missouri law that required a balance in all pharmacies. Torsion balances were historically the type of balances found and utilized in pharmacies. Pharmacists may not be aware that the law has changed and therefore would have them present, especially if they were still in use. Additional reasons for the presence of torsion balances include pharmacist preferences, comfort level for use of a torsion balance, and the potentially prohibitive cost of digital balances if compound prescription volume is relatively small. There are several advantages to using a torsion balance: they are less messy and easier to physically use than some digital balances when weighing semi-solids and liquids as need arises; require less maintenance; can be used in a power outage; do not require a warm-up period; require less frequent calibration compared to digital balances; and have long durability and functionality if properly maintained.

The study population is representative of pharmacies in Missouri as well as nationwide. The percent of those pharmacies that self-identified as one of the three major practice sites in this study (independent, chain, hospital) reflects the percent of Missouri registered pharmacies in 2014. There are 16 pharmacy categories in Missouri, but only one community pharmacy classification, which includes both independent and chain pharmacies. ${ }^{31}$ In Missouri, there were $87.8 \%$ community pharmacies, and $8.2 \%$ hospital pharmacies registered in 2014 , which is quite similar to the results reported herein. The practice site breakdown is also similar to that reported by the

Table 5. Perspectives of Pharmacists In Charge Regarding Torsion Balance Instruction Stratified Based on Type of Balance used and Practice Setting

\begin{tabular}{|c|c|c|c|c|c|c|c|c|c|c|c|c|}
\hline & \multicolumn{3}{|c|}{ Community, Independent } & \multicolumn{3}{|c|}{ Community, Chain } & \multicolumn{3}{|c|}{ Hospital } & \multicolumn{3}{|c|}{ Other } \\
\hline & Yes & No & Total & Yes & No & Total & Yes & No & Total & Yes & No & Total \\
\hline $\begin{array}{l}\text { Pharmacies using Torsion balance } \\
\text { in compounding }\end{array}$ & 54 & 8 & 62 & 43 & 6 & 49 & 6 & 3 & $10^{\mathrm{a}}$ & 8 & 0 & 8 \\
\hline $\begin{array}{l}\text { Pharmacies using Digital balance } \\
\text { in compounding }\end{array}$ & 26 & 25 & 51 & 23 & 28 & 51 & 5 & 3 & 8 & 6 & 6 & 12 \\
\hline $\begin{array}{l}\text { Pharmacies using Both balances } \\
\text { in compounding }\end{array}$ & 0 & 0 & 0 & 2 & 1 & 3 & 0 & 0 & 0 & 0 & 0 & 0 \\
\hline $\begin{array}{l}\text { Pharmacies that Own but do not } \\
\text { compound }\end{array}$ & 10 & 4 & $15^{\mathrm{a}}$ & 23 & 17 & $41^{\mathrm{a}}$ & 2 & 3 & 5 & 2 & 3 & 5 \\
\hline $\begin{array}{l}\text { Total \# of pharmacies which own } \\
\text { a balance }\end{array}$ & & & 128 & & & 144 & & & 23 & & & 25 \\
\hline
\end{tabular}

${ }^{\mathrm{a} O n e}$ pharmacist did not specify a preference

Yes $=$ Teach torsion balance use in pharmacy schools

No $=$ Do not teach torsion balance use in pharmacy schools 


\section{American Journal of Pharmaceutical Education 2017; 81 (5) Article 85.}

NCPA 2015 Digest $^{32}$ of 2014 community pharmacy data. Of a total of 1150 community pharmacies in Missouri, $42 \%$ were reported as independent pharmacies, and $58 \%$ as either traditional chain, mass merchant or supermarket. Of the 303 community pharmacies in this study, $47 \%$ self-identified as independent, and $53 \%$ as chain community pharmacies.

Although the survey data was found to be representative of Missouri as discussed above, the study population that was surveyed also constitutes a limitation. Because more than $50 \%$ of the students enrolled at STLCOP are from Missouri, the survey exclusively targeted pharmacies registered with the Missouri Board of Pharmacy. By limiting the study to Missouri, no definitive comment can be made on the prevalence of using torsion balances nationwide. However, the findings in this study are likely reflective of many other states as well given the distinct differences in terms of population densities among the surveyed eight Missouri regions as well as the compound user demographics and differences in practice site composition compared to nationwide statistics. A recent study ${ }^{9}$ on compounded medications in insured patients reported that the national average for prevalence of compound users was $1.4 \%$, with Missouri's prevalence reported as $1.5 \%$ to $1.7 \%$. Hence, the Missouri data is comparable to the data reported nationwide. The breakdown of community practice sites in the study reported herein is similar to what is observed nationwide. The NCPA 2015 digest reported $37 \%$ as independent pharmacies, and $63 \%$ as either traditional chain, mass merchant or supermarket, which is comparable to the findings discussed herein. $^{32}$

Pharmacists were also queried on their view of torsion balance instruction. Their opinion is important because they are the ones who are responsible for prescription compounding and are knowledgeable about pharmacy needs and demands. The majority of pharmacists who participated in this survey $[59.7 \%$ of all respondents, whether they owned or used a balance or not] advocated for the continuation of torsion balance instruction. As expected, the majority of pharmacies that exclusively owned and used torsion balances advocated for their continued instruction. Similarly, the pharmacists at pharmacies that do not own a balance advocated for continued torsion balance instruction. An explanation for these results could be that these pharmacists are aware of the prevalence of torsion balances in pharmacies and, therefore, pharmacists should know how to use them. Surprisingly, pharmacists who exclusively use a digital balance to compound were almost equally divided in advocating for torsion balance instruction.

\section{CONCLUSION}

As shown by this study, torsion balances are not obsolete and are used extensively in Missouri pharmacies. The data support instruction and use of torsion and digital balances in the Pharmaceutics laboratory. Based on the findings discussed herein, the ability to use torsion balances remains substantially important for educating skilled pharmacists. It is the recommendation of the Pharmaceutics team at STLCOP that pharmacy students continue to be taught torsion balance technique.

\section{ACKNOWLEDGMENTS}

Financial resources for this project were provided by the STLCOP Basic and Pharmaceutical Sciences departmental funds.

\section{REFERENCES}

1. Newton DW. Clinical perspectives in compounding: compounding gains and losses since I met "careless arithmetic nullifies careful compounding." Int J Pharm Compd. 2015;19(6): 444-446.

2. Accreditation Council of Pharmacy Education. Accreditation standards and key elements for the professional program in pharmacy leading to the doctor of pharmacy degree. Standards 2016. https:// www.acpe-accredit.org/pdf/Standards2016FINAL.pdf.

3. Shrewsbury R, Augustine S, Birnie C, et al. Assessment and recommendations of compounding education in AACP member institutions. Am J Pharm Educ. 2012;76(7):Article S9.

4. McPherson TB, Fontane PE, Jackson KD, et al. Prevalence of compounding in independent community pharmacy practice. $J \mathrm{Am}$ Pharm Assoc. 2006;46(5):568-573.

5. Cauthon KAB, Bowman BJ, Gurney MK. Compounding practices and beliefs of Arizona pharmacists. Int J Pharm Compd. 2013;17(2): 154-161.

6. What is compounding? International Academy of Compounding Pharmacists. http://www.iacprx.org/?page=1. Accessed March 30, 2016.

7. Total number of retail prescription drugs filled at pharmacies, the Henry J. Kaiser Family Foundation. http://kff.org/other/state-indicator/ total-retail-rx-drugs/. Accessed February 4, 2016.

8. Accreditation for Compounding Pharmacies, National Community Pharmacist Association. http://www.ncpanet.org/ solutions/pharmacy-practice-tools/accreditation-for-compoundingpharmacies. Accessed March 30, 2016.

9. McPherson T, Fontane P, Iyengar R, Henderson R. Utilization and costs of compounded medications for commercially insured patients, 2012-2013. J Manage Care Spec Pharm. 2016;22(2): 172-181.

10. PCCA (Professional Compounding Centers of America). What is PCCA? http://www.pccarx.com/prescribers/what-is-pcca-prescribers. Accessed February 4, 2016.

11. International Academy of Compounding Pharmacists. What is IACP? http://www.iacprx.org/?page=100. Accessed February 4, 2016 .

12. Compounding Pharmacies in the US: Market Research Report. IBISWorld. https://www.ibisworld.com/industry-trends/specializedmarket-research-reports/life-sciences/healthcare-services/ compounding-pharmacies.html. Accessed March 31, 2016. 


\section{American Journal of Pharmaceutical Education 2017; 81 (5) Article 85.}

13. US Pharmacopeia. $<1176>$ Prescription balances and volumetric apparatus. 2015; The United States Pharmacopeial Convention. 14. Allen LV, Popovich NG, Ansel HC. $9^{\text {th }}$ ed. Ansel's Pharmaceutical Dosage Forms and Drug Delivery Systems. Philadelphia, PA: Lippincott Williams and Wilkins; 2011.

15. US Pharmacopeia. $<1251>$ Weighing on an analytical balance. 2015; The United States Pharmacopeial Convention.

16. Shrewsbury RP, Deloatch KH. Accuracy in prescriptions compounded by pharmacy students. Int J Pharm Compd. 1998;2(2):139-142.

17. Bilger R, Salama NN, Chereson R. Assessment of student compounding skills at St. Louis College of Pharmacy. AACP Annual Meeting Pharmacy Education, Chicago, IL, July 13-17, 2013, Am J Pharm Educ. 2013;77(5):109.

18. US Pharmacopeia. $<41>$ Balances. 2015; The United States

Pharmacopeial Convention.

19. US Pharmacopeia. $<795>$ Pharmaceutical compounding nonsterile preparations. 2015; The United States Pharmacopeial Convention.

20. Missouri Department of Agriculture. Scales. http://agriculture. mo.gov/weights/device/scales.php. Accessed April 1, 2016. 21. Newton DW. Balances and weighing accuracy. Int J Pharm Compd. 1998;2(5):376-377.

22. Kadi A, Francioni-Proffitt D, Hindle M, Soine W. Evaluation of basic compounding skills of pharmacy students. Am J Pharm Educ. 2005;69(4):508-515.

23. Missouri Board of Pharmacy Statutes and Rules. 2014. Pharmacy Standards of Operation (20CSR 2220-2.010). http://pr.mo.gov/boards/ pharmacy/pharmacylawbook.pdf. Accessed February 11, 2016.

24. Texas State Board of Pharmacy Administrative Code.

Pharmacies compounding non-sterile preparations (Rule §291.131).
http://texreg.sos.state.tx.us/public/readtac\$ext.TacPage?sl= $\mathrm{R} \& \mathrm{app}=9 \& \mathrm{p} \_$dir $=\& \mathrm{p} \_r l o c=\& \mathrm{p} \_$tloc $=\& \mathrm{p} \_\mathrm{ploc}=\& \mathrm{pg}=1 \& \mathrm{p} \_$tac $=$ $\& \mathrm{ti}=22 \& \mathrm{pt}=15 \& \mathrm{ch}=291 \& \mathrm{rl}=131$. Accessed April 1, 2016. 25. Oregon Board of Pharmacy Administrative Rules. Minimum equipment requirements (855-041-1035). http://arcweb.sos.state.or. us/pages/rules/oars_800/oar_855/855_041.html. Accessed March 31, 2016.

26. Wisconsin Department of Safety and Professional Services. Pharmacy licenses and equipment (Phar 6.06). http://docs.legis. wisconsin.gov/code/admin_code/phar/6/06. Accessed March 31, 2016.

27. Virginia Board of Pharmacy Laws \& Regulations. March 24, 2016. Required minimum equipment or resources (18VAC110-20170). http://www.dhp.virginia.gov/pharmacy/pharmacy_laws_regs. htm. Accessed March 28, 2016.

28. Illinois Department of Financial and Professional Regulation. Pharmacy Practice Act. (Sections 1330.610 and 1330.640). http:// www.ilga.gov/commission/jcar/admincode/068/06801330sections. html. Accessed March 28, 2016

29. Krejcie RV, Morgan DW. Determining sample size for research activities. Educ Psychol Measure. 1970;30(3):607-610.

30. US Census Bureau. Population, Housing Units, Area, and Density: 2010-State - County for Missouri. https://factfinder.census. gov/faces/nav/jsf/pages/community_facts.xhtml\# Accessed April 2, 2016.

31. Missouri Board of Pharmacy. Pharmacy Change of Classification Application. http://pr.mo.gov/boards/pharmacy/375-0475.pdf. Accessed March 30, 2016.

32. National Community Pharmacists Association: NCPA 2015 Digest. 2015;9-11. 


\section{American Journal of Pharmaceutical Education 2017; 81 (5) Article 85.}

Appendix 1 Torsion Balance Survey

1. Please indicate the practice setting of the pharmacy in which you are pharmacist-in-charge.

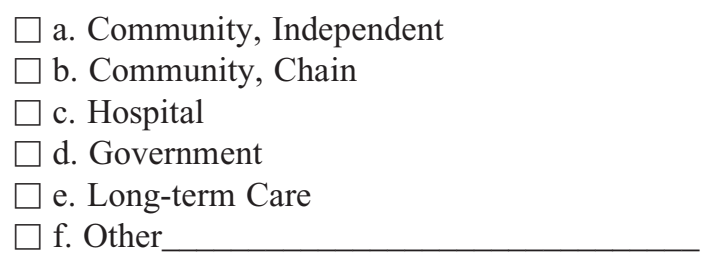

2. Does your pharmacy have any balances?

a. Yes

$\square$ b. No; Thank you for completing this questionnaire. Please return survey to the address below.

3. If your pharmacy has a balance, which type(s) is/are found?

a. Torsion balance Quantity

b. Electronic balance Quantity___ Brand

4. Please indicate which type of balance(s) is/are being used for compounding.

$\square$ a. Torsion balance

$\square$ b. Electronic balance

$\square$ c. Neither; we do not compound at this pharmacy.

5. On average, how many prescriptions does your pharmacy compound (nonsterile) each week? Note - Compounding does

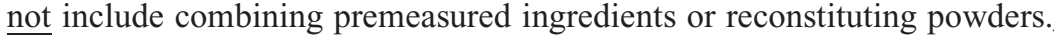

6. Do you think students should continue to learn how to use a torsion balance?

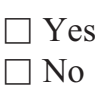

Thank you for completing this survey.

Please mail to: Rhonda Bilger

St. Louis College of Pharmacy

4588 Parkview Place

St. Louis, MO 63110 